\section{A Greenhouse-based Inoculation Protocol for Fungi Causing Crown Rust and Stem Rust Diseases of Kentucky Bluegrass Turf}

\author{
Lisa A. Beirn, William A. Meyer, and Bruce B. Clarke \\ Department of Plant Biology and Pathology, Rutgers University, 59 Dudley \\ Road, New Brunswick, NJ 08901
}

\author{
Jo Anne Crouch ${ }^{1}$ \\ Systematic Mycology and Microbiology Laboratory, USDA-ARS, 10300 \\ Baltimore Avenue, Beltsville, MD 20705
}

Additional index words. infectivity, Poa pratensis, Puccinia coronata, Puccinia graminis

\begin{abstract}
Rusts are destructive fungal diseases that can cause severe thinning and unattractive discoloration of kentucky bluegrass (KBG; Poa pratensis L.). Currently, turfgrass breeding programs rely on field evaluations to screen KBG germplasm for rust resistance; methods that are expensive, labor intensive, and require large turf areas. The availability of a greenhouse-based assay to perform prescreening of KBG germplasm for resistance to rust diseases before field trials would allow breeders to remove the poorest performing plants before field evaluations thus enhancing breeding efficiency. In this study, we set out to develop a reliable, low-cost greenhouse inoculation protocol for the two most common rust pathogens of KBG in temperate growing regions: Puccinia coronata and Puccinia graminis, the causal agents of crown and stem rust, respectively. Using a modified inoculation assay and custom-built plexi-glass chambers adapted from protocols used for cereal rust pathogens, urediniospores of crown and stem rust fungi developed on inoculated plants 10 to 14 days postinoculation. Real-time polymerase chain reaction (PCR) assays, disease symptomology, and morphology of urediniospores confirmed the presence and identity of both rust pathogens from inoculated host tissue. The inoculation protocols described here represent an effective method to accelerate screening of KBG germplasm for resistance to crown and stem rust diseases. Infection of KBG plants in the greenhouse will also allow breeders to maintain populations of crown and stem rust fungi throughout the year, providing a reliable and ongoing source of pathogen inoculum for experimentation and screening in the future.
\end{abstract}

Rust (Puccinia sp.) is a common fungal disease of kentucky bluegrass (KBG; Poa pratensis $\mathrm{L}$.), one of the most commonly used cool-season turfgrasses on athletic fields, recreation areas, sod farms, and residential lawns. Diseased turf typically exhibits an unsightly orange/brown coloration, and severe infections can result in extensive turf loss in susceptible KBG stands (Bonos et al., 2006). In the

Received for publication 15 May 2015. Accepted for publication 2 Sept. 2015.

Funding for this research was provided by the Rutgers Center for Turfgrass Science, the U.S. Department of Agriculture (USDA), and the USDA Agricultural Research Service.

We gratefully acknowledge Mark Peacos for assistance building the misting chamber and Les Szabo, Matthew Rouse, Jerry Johnson, and Samuel Stoxen for graciously hosting Lisa Beirn and demonstrating inoculation protocols used in cereal crops at the USDA-ARS Cereal Disease Laboratory.

Mention of trade names or commercial products in this publication is solely for the purpose of providing specific information and does not imply recommendation or endorsement by the USDA.

${ }^{1}$ Corresponding author. E-mail: JoAnne.Crouch@ ars.usda.gov. hindered by the inability to evaluate turfgrass cultivars in the greenhouse or growth chambers under controlled environmental conditions. At present, turfgrass breeders are reliant on natural field infections to evaluate their germplasm. This can be a complicated and unreliable process, as multiple rust species can infect KBG (Beirn et al., 2011) and environmental conditions do not always favor uniform disease development (Welty and Barker, 1993) making selections for resistant cultivars difficult. In addition, fundamental knowledge of the biology and infectivity of the causal agents of rust diseases is lacking, thus slowing progress in the development of resistance to multiple fungal races or strains.

Two primary factors have contributed to the limited advancements in the control and study of turfgrass rust fungi: 1) the biotrophic lifestyle of the fungal rust pathogens precludes the establishment of axenic cultures and production of pathogen inoculum for experiments, and 2) previous inoculation protocols for evaluating plants in the growth chamber or greenhouse have been difficult to reproduce. The obligate nature of rust fungi makes propagation in culture extremely difficult or impossible in the absence of the host plant (Agrios, 2005). Attempts to grow graminicolous rust fungi in culture in the laboratory have met with varying levels of success, and have frequently produced nonrepeatable results (Huang et al., 1990; Williams et al., 1966, 1967). Detached leaf assays have been used to maintain cultures of the crown rust fungus ( $P$. coronata) from oats (Avena sativa L.); however, it remains to be determined if this technique can be used to screen healthy oat plants for resistance to rust due to the confounding physiological processes associated with leaf senescence (Jackson et al., 2008).

The complexities surrounding axenic culturing of graminicolous rust fungi has been overcome in the cereal rust system, where inoculation of cool-season cereal crops, including wheat (Triticum aestivum L.), barley (Hordeum vulgare L.), and oats, is now a routine procedure that has been performed to screen germplasm for several decades (Jackson et al., 2008). In the cereal rust system, the procedure entails: 1) spraying a mineral oil suspension of viable urediniospores onto susceptible plants, 2) placing plants in a dew chamber overnight to incubate, 3) moving inoculated plants the following day to a greenhouse where urediniospores are allowed to infect plant tissue, a process that takes $\approx 10 \mathrm{~d}$, and 4 ) selecting a single uredinium to mature once pustules erupt (Carson, 2008). Ultimately, spores from the single pustule are harvested and used to inoculate healthy plant material, thus increasing the inoculum of a single rust isolate (Carson, 2008). This method ensures pathogen homogeneity and produces copious amounts of genetically identical spores that can then be used for advanced molecular analyses or to screen germplasm.

A similar procedure has been effectively adapted to other grass systems, such as in 
Italian ryegrass (Lolium multiflorum Lam.), where inoculations of the crown rust pathogen were used to study resistance markers in the host plant (Studer et al., 2007). Likewise, the successful inoculation of KBG, perennial ryegrass (Lolium perenne L.), and tall fescue (Festuca arundinacea Schreb.) has also been previously described for the stem rust fungus (Pfender, 2001b, 2003, 2009b); however, the reported protocols have not been successfully used to inoculate turfgrass with multiple rust species simultaneously. In addition to stem rust, at least one additional rust disease, crown rust, is known to occur on KBG in temperate regions (Beirn et al., 2011). Resistance to this disease is now an important target of perennial ryegrass breeding programs (Bonos et al., 2006). At present, there remains no universal inoculation protocol for both crown and stem rust diseases on KBG, although unsuccessful attempts have been made by several laboratories (S.A. Bonos, personal communication). The development of an effective inoculation protocol for crown and stem rust fungi would allow breeders to screen large numbers of KBG selections and cultivars in the greenhouse for resistance to rust species/races in a convenient, reproducible manner before evaluating germplasm in the field, thus reducing reliance on inconsistent natural infection. It would also allow researchers to genetically purify rust strains for pathogen analysis at the molecular level. Therefore, our objective in this study was to develop a reliable inoculation protocol for turfgrass rust fungi by adapting and modifying techniques developed and used in the cereal rust system.

\section{Materials and Methods}

Turfgrass hosts. Over $300 \mathrm{KBG}$ cultivars were evaluated in field trials for their susceptibility to stem and crown rust diseases from 2007 to 2014 at the Rutgers University Plant Science Research and Extension Farm in Adelphia, NJ. Trials relied on naturally occurring rust infections. Cultivars were visually rated on a scale of 1 to 9 , where 1 represented the most disease and 9 the least disease. More specifically, $1=90 \%$ to $100 \%$, $2=75 \%$ to $90 \%, 3=65 \%$ to $75 \%, 4=50 \%$ to $65 \%, 5=40 \%$ to $50 \%, 6=30 \%$ to $40 \%, 7=$ $20 \%$ to $30 \%, 8=10 \%$ to $20 \%$, and $9=0 \%$ to $10 \%$ leaf area exhibiting signs of foliar infection. From this data, three rust susceptible KBG cultivars, Diva, Bewitched, and Ulysses, (average disease severity $=5.9,6.4,4.0$, respectively, where $9=$ no disease) were selected for use in greenhouse-based inoculation trials. KBG cultivars were seeded $(0.5 \mathrm{~g}$ of seed per pot) in $10-\mathrm{cm}$ pots filled with Fafard Canadian Grow Mix 2 (Agawam, MA). Average temperature within the greenhouse was $19{ }^{\circ} \mathrm{C}$, with natural sunlight ranging between 350 and $900 \mu \mathrm{mol} \cdot \mathrm{m}^{-2} \cdot \mathrm{s}^{-1}$. Seedlings received daily overhead irrigation. To control outbreaks of powdery mildew [Blumeria graminis (DC.) E.O. Speer] during seedling establishment, elemental sulfur was burned in a sulfur vaporizer (Better Grow
Hydro, Bell, CA) overnight, for a period of $8 \mathrm{~h}$. Two sulfur treatments were applied before rust inoculations; one treatment when plants were 1 week postgermination followed by a second application 1 week later. No additional pesticides or fertilizers were applied.

Fungal isolates. Isolates of the crown and stem rust pathogens were collected during the summer of 2009 and 2010 from natural infections of KBG at the Rutgers Turfgrass Research Farm in Adelphia, NJ using a 19-L wet dry vacuum and stored at $-70{ }^{\circ} \mathrm{C}$ as desiccated urediniospores in 50-mL polypropylene tubes (BD Falcon, Bedford, MA). Before inoculation experiments, urediniospores were removed from $-70{ }^{\circ} \mathrm{C}$ storage and were allowed to acclimate to room temperature for 1 to $2 \mathrm{~h}$. Urediniospore germination was tested by streaking spores on $2 \%$ water agar and incubating the plates on the laboratory bench top for several hours; only samples with $\geq 80 \%$ germination were used for inoculations. One isolate of each rust species with sufficient germination was used for these studies.

Inoculation procedure. All KBG cultivars were inoculated separately with one isolate of each rust species. The inoculum consisted of $0.10 \mathrm{~g}$ of urediniospores suspended in $1 \mathrm{~mL}$ of light mineral oil (Fisher Scientific, Pittsburgh, PA) per plant. The spore suspension was prepared in a $1.5-\mathrm{mL}$ microcentrifuge tube and mixed by vortexing for $10 \mathrm{~s}$. The mineral oil/spore suspension was sprayed onto the foliage of 5 week postemergent KBG plants in a fume hood using a Badger 150 airbrush paint sprayer (Franklin Park, IL) with a bottom feed head adapter. Noninoculated KBG plants were sprayed with water and served as a negative control for all experiments. Inoculated plants were allowed to dry for $\approx 1 \mathrm{~h}$ in the fume hood, and then transferred to a custom-made plexi-glass misting chamber (Fig. 1A). The plexi-glass chamber measured $91.5 \mathrm{~cm} \times 63.5 \mathrm{~cm} \times 76.2 \mathrm{~cm}$ and was constructed with $7.9-\mathrm{mm}$ plexiglass. A humidifier (Herrmidifier, Phoenix, AZ) provided the source of mist in the chamber. Inoculated plants were incubated in the misting chamber for $10 \mathrm{~h}$ overnight, with misting/dry cycles alternating every $30 \mathrm{~min}$. The air temperature and relative humidity inside the misting chamber fluctuated between 18 and $20{ }^{\circ} \mathrm{C}$ and $88 \%$ and $99 \%$, respectively. For stem rust inoculations, the misting chamber was covered with a dark cloth during the first $2 \mathrm{~h}$ of incubation to ensure a sufficient overnight dark period (Pfender, 2001b). After $10 \mathrm{~h}$, the misting chamber door was opened and plants were allowed to acclimate for 1 to $2 \mathrm{~h}$ before moving to the greenhouse in a custom-built wood-framed incubation chamber cubes, measuring $30.5 \mathrm{~cm} \times 30.5 \mathrm{~cm}$ on all sides. Three of the six sides of the incubation chambers were covered with 4-mm translucent plastic (Film-Gard, Inc.) to keep plants separated, while still allowing exposure to light (Fig. 1B). Plants previously inoculated with rust spores were kept in the woodframed bench top incubation chamber cubes

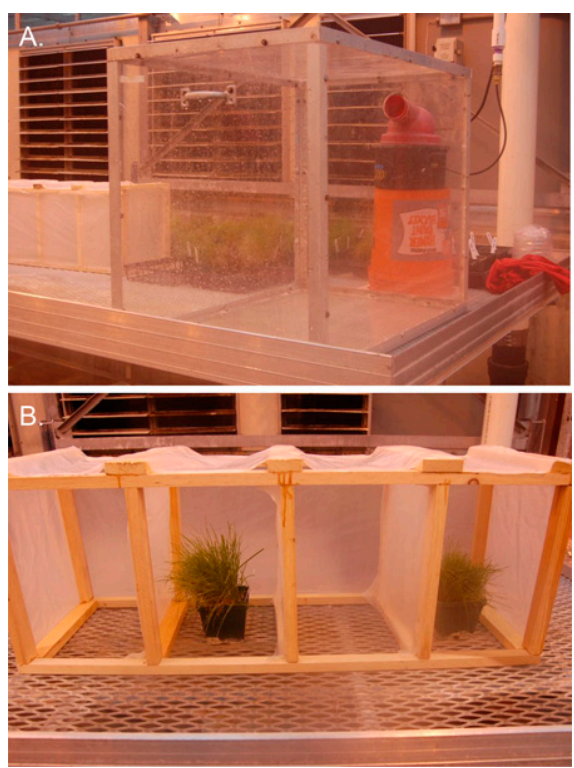

Fig. 1. Photographs of custom-built inoculation supplies. (A) The plexi-glass misting chamber used to incubate kentucky bluegrass plants previously inoculated with rust species. A hole was cut through the back wall to allow insertion of a humidifier, which served as the misting source. (B) Wood-framed inoculation chambers to prevent the spread of urediniospores.

in the greenhouse until pustules developed. Daytime temperatures were maintained between 19 and $21^{\circ} \mathrm{C}$ beginning $2 \mathrm{~h}$ after dawn and ending $1 \mathrm{~h}$ before dusk. Night temperatures were maintained between 18 and $20^{\circ} \mathrm{C}$. The preset light intensity conditions were as follows: overhead halide lighting (PL Light Systems, Ontario, CA) illuminated the plants between the hours of 7:00 AM and 7:00 PM, only if the light intensity dropped below 350 $\mu \mathrm{mol} \cdot \mathrm{m}^{-2} \cdot \mathrm{s}^{-1}$. If the light intensity exceeded $900 \mu \mathrm{mol} \cdot \mathrm{m}^{-2} \cdot \mathrm{s}^{-1}, 50 \%$ of the greenhouse was shaded with shade cloth (Ludvig Svensson, Charlotte, NC) to reduce light levels. If the light intensity reached $>1200 \mu \mathrm{mol} \cdot \mathrm{m}^{-2} \cdot \mathrm{s}^{-1}$, $95 \%$ of the greenhouse was shaded by the shade cloth to reduce light levels.

All plants were watered at the base to avoid wetting the inoculated foliage during the course of the experiments. Inoculated plants were monitored until rust pustules developed.

Spore morphology and real-time PCR. Upon uredinia development, spores were harvested by hand to confirm species identity. Morphological evaluations to measure urediniospore size, shape, color, and the number of germ pores were conducted using Cummins (1971) as a guide. Germ pores were stained and visualized using aniline-blue squash technique (Jennings et al., 1989) and spores were photographed using an Olympus BX41 clinical microscope (New York/New Jersey Scientific, Middlebush, NJ). Photomicrographs were generated using MagnaFIRE v.2.0 software (Olympus, Inc., Melville, NY).

Urediniospore DNA was extracted using the OmniPrep Extraction Kit (G-Biosciences, MD Heights, MO) and each sample was 
screened against real-time PCR probes designed for the detection of crown and stem rust fungi from turfgrass hosts using ribosomal DNA markers (Beirn et al., 2011). Real-time PCR reactions were performed using a Cepheid SmartCycler (Cepheid, Sunnyvale, CA) in $25-\mu \mathrm{L}$ Cepheid tubes. Cepheid's Smartmix HM lyophilized PCR master mix was used for all reactions with a final probe concentration of $1 \mu \mathrm{M}$ and primer concentration of $10 \mu \mathrm{M}$. Cycling conditions were as follows: initial denaturation at $95^{\circ} \mathrm{C}$ for $120 \mathrm{~s}$, followed by 45 cycles of $95{ }^{\circ} \mathrm{C}$ for $3 \mathrm{~s}$, and $60{ }^{\circ} \mathrm{C}$ for $39 \mathrm{~s}$. Samples were considered positive if the fluorescent threshold (30) was crossed before cycle 40, whereas negative samples produced cycle threshold $\left(\mathrm{C}_{\mathrm{T}}\right)$ values equal to zero.

\section{Results}

Turfgrass hosts. Complete data from KBG field evaluations is archived at http:// turf.rutgers.edu/research/reports/index.html. Briefly, KBG cultivars Bewitched, Diva, and Ulysses displayed susceptibility to rust diseases in the field. Cultivars were only mildly susceptible to crown rust (average disease severity range $=6.3$ to 6.9 ), except for Diva, which displayed extensive susceptibility (4.9) on one rating date in one trial in 2009 (Table 1). For stem rust disease, 'Diva' and 'Bewitched' exhibited the least amount of disease (average diseases severity 6.4 and 5.6, respectively), whereas 'Ulysses' was highly susceptible to this disease (average disease severity 3.4) (Table 1).

Inoculation results. Pustules of crown and stem rust were observed on all inoculated cultivars $\approx 10$ to $14 \mathrm{~d}$ postinoculation (Figs. 2A and 3A). Leaf lesions were not observed on inoculated plants and noninoculated plants never developed rust pustules. Pustules of the crown rust fungus were a bright yellow-orange color, formed on the adaxial leaf surface, and were slightly oblong to round in shape. Uredinia were randomly distributed from midleaf to the leaf tips of inoculated cultivars, reflecting the points of inoculation. Infection developed on $\approx 50 \%$ of the total leaf surface area for the cultivars Bewitched and Diva, while Ulysses exhibited $\approx 30 \%$ infection. No infection was seen on leaf sheaths on any cultivars. Other than uredinia, infected plants appeared healthy and no chlorotic or necrotic lesions were present.

Uredinia of the stem rust pathogen were dark red in color, located on the adaxial leaf surface, and were oblong in shape. Uredinia were only located midleaf, with no infection on the leaf sheaths or leaf tips. All three cultivars exhibited $\approx 30 \%$ infection on the leaf surface area, which was typically located on leaves exposed to the pot perimeter. No chlorosis or necrotic lesions were present. The observed symptoms and signs were consistent with those reported by Cummins (1971) and Smiley et al. (2005).

Photographs of crown and stem rust uredinia and urediniospores are presented in

Table 1. Susceptibility of kentucky bluegrass cultivars to crown and stem rust disease in turf trials at Adelphia, NJ from 2007 to 2014.

\begin{tabular}{|c|c|c|c|c|c|c|c|c|c|c|}
\hline \multirow[b]{2}{*}{ Cultivar } & \multicolumn{2}{|c|}{ Crown rust ${ }^{\mathrm{z}}$} & \multirow{2}{*}{$\begin{array}{c}\text { Avg } \\
\text { severity }\end{array}$} & \multicolumn{6}{|c|}{ Stem rust } & \multirow{2}{*}{$\begin{array}{c}\text { Avg } \\
\text { severity }\end{array}$} \\
\hline & 2009 & $2009^{x}$ & & 2007 & $2009^{x}$ & 2010 & 2011 & 2013 & 2014 & \\
\hline Bewitched & $7.7^{\mathrm{v}}$ & 6 & 6.9 & $\mathrm{~N} / \mathrm{A}^{\mathrm{w}}$ & 7.5 & 6.0 & 6.7 & 4.0 & 3.7 & 5.6 \\
\hline Diva & 7.7 & 4.9 & 6.3 & 6.3 & 7.3 & 6.0 & 6.7 & 6.3 & 5.7 & 6.4 \\
\hline Ulysses & 6.7 & $\mathrm{~N} / \mathrm{A}^{\mathrm{w}}$ & 6.7 & 2.0 & 1.8 & 3.7 & 6.3 & 3.3 & $\mathrm{~N} / \mathrm{A}^{\mathrm{w}}$ & 3.4 \\
\hline
\end{tabular}

${ }^{\mathrm{z}}$ Two separate field trials were rated in 2009 for their susceptibility to crown rust.

${ }^{y}$ Average across all years for each rust disease.

${ }^{x}$ Data shown is an average from two rating dates in 2009.

${ }^{\mathrm{w}}$ Cultivar was not included in listed trials.

"Ratings are on a scale of 1 to 9 , where $1=$ most disease and $9=$ least disease.
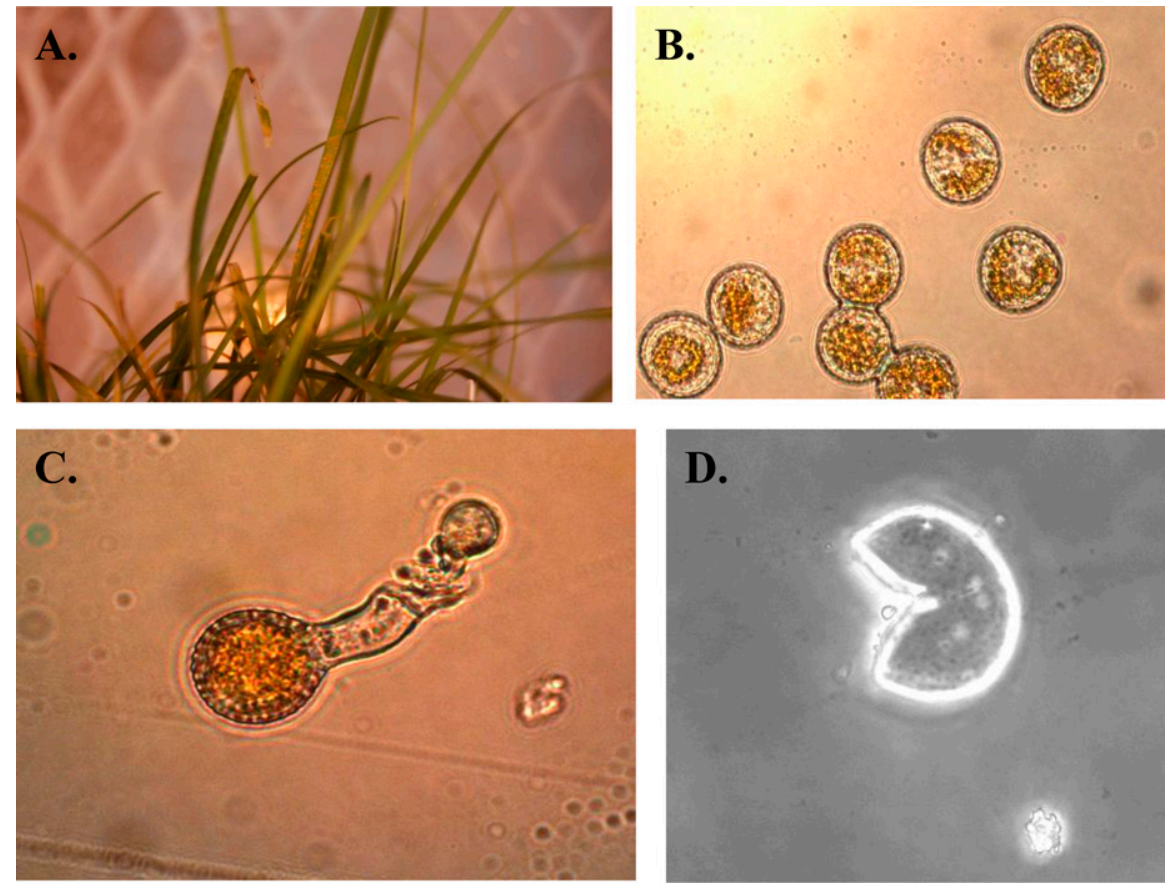

Fig. 2. (A) Uredinia of the crown rust fungus on inoculated kentucky bluegrass plants, (B) urediniospores $(\times 400)$, (C) a germinating urediniospore $(\times 400)$, and $($ D) a squashed urediniospore with visible, scattered germ pores $(\times 400)$.

Figs. 2 and 3. Urediniospores harvested from the infected plants were evaluated for spore size, shape, color, and number of germ pores. Urediniospores of the crown rust pathogen were 20 to $25 \mu \mathrm{m} \times 17$ to $22 \mu \mathrm{m}$, mostly ellipsoid, yellowish to orange, and had four to six scattered germ pores (Fig. 2B-D), which was consistent with descriptions of the fungus (Cummins, 1971) and the isolate used to inoculate the plants. Urediniospores of the stem rust pathogen were 26 to $39 \mu \mathrm{m} \times 16$ to $23 \mu \mathrm{m}$, globoid or oblong, dark red to brown, and had three equatorial germ pores (Fig. 3BD), which was consistent with descriptions of the fungus (Cummins, 1971) and the isolate used to inoculate the plants.

Real-time PCR confirmation. Crown and stem rust fungi were detected from all inoculated KBG plants using real-time PCR probes, with average $C_{T}$ values of 26.88 and 28.79, respectively (Fig. 4A and $\mathrm{B}$ ). Noninoculated controls produced $\mathrm{C}_{\mathrm{T}}$ values of 0.00 . No cross-contamination was observed between plants inoculated with isolates of both stem and crown rust.

\section{Discussion}

The primary objective of this study was to develop a reliable inoculation protocol for crown and stem rust fungi commonly observed on KBG in temperate regions (Beirn et al., 2011; Smiley et al., 2005). Three KBG cultivars that displayed susceptibility to rust in the field were successfully inoculated with both crown and stem rust under controlled conditions. Protocols for inoculating Italian ryegrass with crown rust fungi (Studer et al., 2007) and KBG with stem rust fungi (Pfender, 2009b) are available; however, the environmental conditions described in these studies are different for each fungal species. Therefore, it is not known whether these procedures could be used for multiple species of rust fungi without modification. In contrast, the inoculation protocol developed in our study can be used for both crown and stem rust fungi, allowing KBG cultivars to be evaluated for susceptibility to both diseases simultaneously. In addition, our protocol makes use of commonly available supplies 

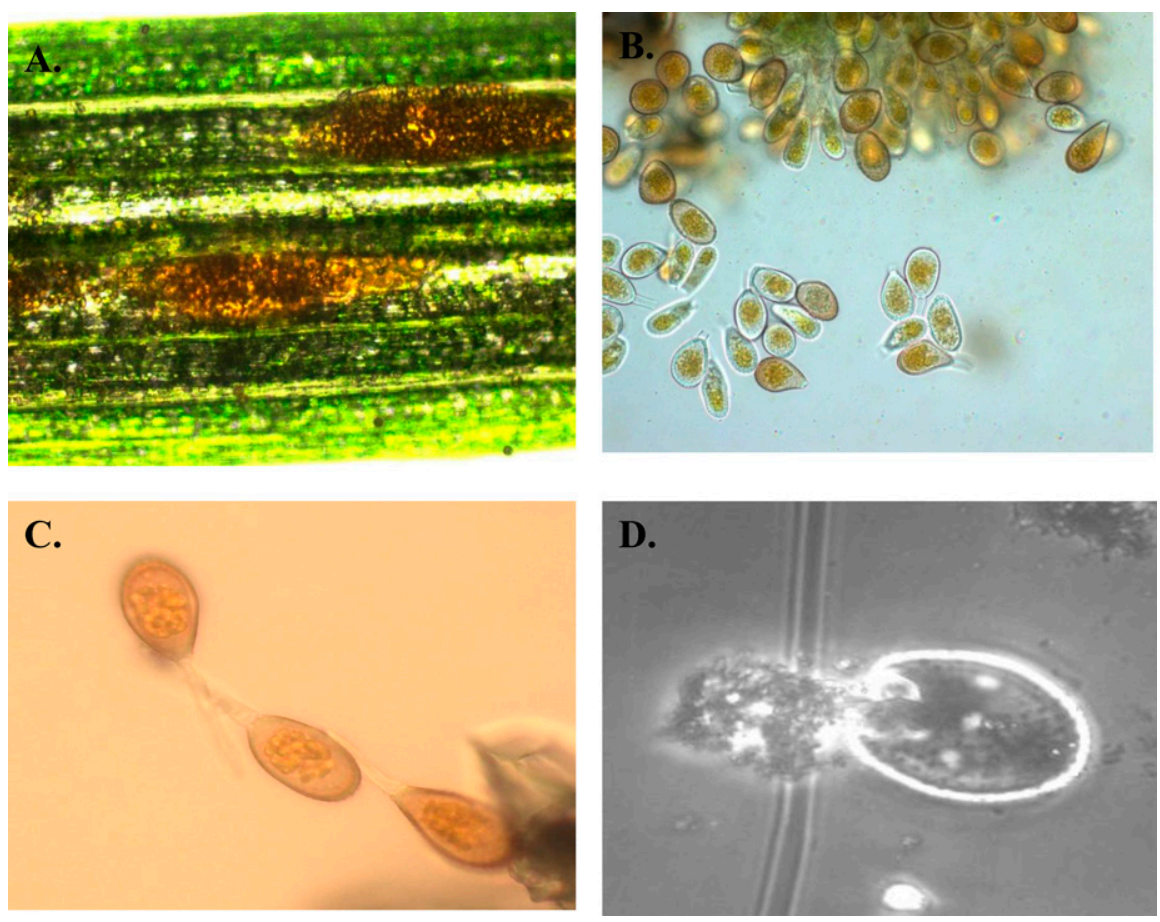

Fig. 3. (A) Uredinial sori of the stem rust fungus erupting from inoculated kentucky bluegrass leaf, (B) urediniospores $(\times 100),($ C $)$ urediniospores $(\times 400)$, and $($ D) a squashed urediniospore with visible, equatorial germ pores $(\times 400)$.
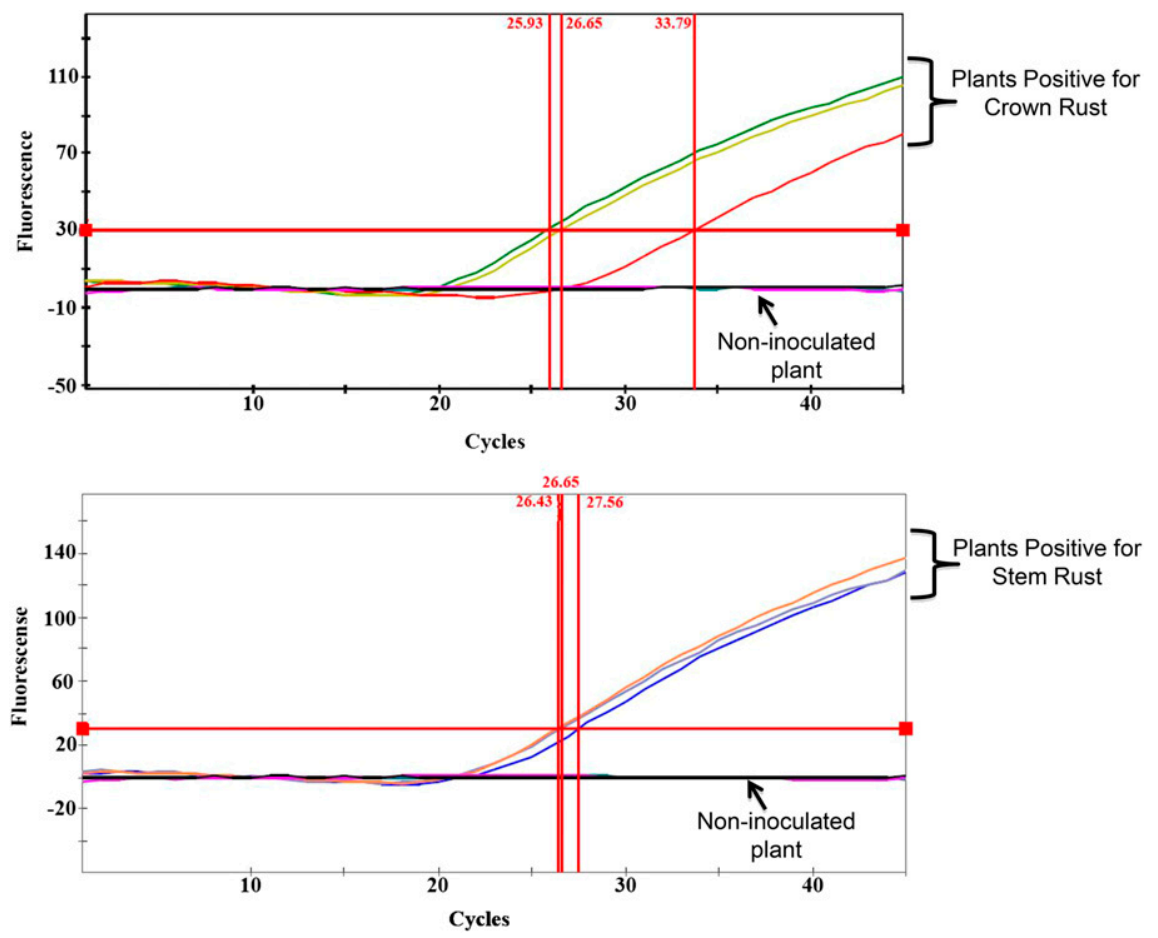

Fig. 4. Real-time PCR data from inoculation experiments. Only the target of interest produced fluorescence. (A) Fluorescence of crown rust fungal isolate CRV-A1 from inoculated kentucky bluegrass (KBG) cultivars Bewitched, Diva, and Ulysses'. (B) Fluorescence of stem rust fungal isolate SRV-A2 from inoculated KBG cultivars Bewitched, Diva, and Ulysses.

(a vacuum, airbrush paint sprayer, humidifier, generic mineral oil) and easily constructed equipment (misting chamber, incubation chambers), allowing it to be readily implemented in a cost-effective manner by laboratories who do not have access to the large-scale, customized equipment currently used by research groups studying cereal rust fungi. Moreover, when used in combination with real-time PCR assays (Beirn et al., 2011), our inoculation protocol provides a powerful tool for turfgrass breeders to assess infectivity levels in a quantitative manner across KBG cultivars. For example, real-time PCR has been employed in alfalfa to identify Phytophthora-resistant germplasm among a large collection of plants that could not be easily distinguished using visual rating systems (Vandemark and Barker, 2003). Implementing a similar system in turfgrass breeding programs would allow breeders to quantify rust infection and more easily distinguish between KBG plants displaying high levels of resistance to crown and/or stem rust disease.

The development of a successful crown and stem rust inoculation protocol for KBG marks a major advance and should help researchers gain a better understanding of turfgrass rust fungi in the future. Turfgrass breeders now have a reliable method for screening KBG cultivars in the greenhouse or growth chamber to assess resistance to two rust species before planting in the field, thus greatly reducing the time and resources required to develop rust-resistant cultivars. In addition, breeders will no longer be reliant on natural rust infections to evaluate turfgrass germplasm, thereby allowing research to continue without having to depend on unreliable and often nonuniform disease outbreaks in the field. This procedure may also be useful as a foundation for establishing a standardized set of race differentials in $\mathrm{KBG}$; a regular practice used in the cereal rust system to determine the emergence and severity of new rust races against a series of known host plant resistance genes (Roelfs, 1984). In the study of cereal rusts, a defined set of host plant varieties, each with a known single resistance gene, is screened against different rust strains and evaluated for qualitative differences in the disease reaction to each pathogen. A major change in the disease reaction among these differentials in KBG would signal a novel physiological race. While we do not yet fully understand the intricacies of rust resistance genes in KBG, early evidence supports the existence of a single dominant resistance gene in this pathosystem (Braverman, 1965). This suggests that race differentials similar to those used in cereal crops could be beneficial for evaluating resistant KBG cultivars for new races of rusts.

In addition to screening KBG cultivars before planting in the field, our protocol can also be used to study the biology and virulence of rust pathogens. For example, the three KBG cultivars used in this study were selected based on their overall susceptibility to stem and crown rust disease in field evaluations over several years. We were able to inoculate all three cultivars with both stem and crown rust disease under controlled conditions; however, we were not able to confirm that these isolates were identical to those causing symptoms in the field on each rating date. This shortcoming currently makes it difficult to correlate infection in the greenhouse with disease ratings in the field. The variable response of the three KBG cultivars over the rating period suggests that multiple races of the pathogens may be 
responsible for the shifts in rust susceptibility previously observed in the field (Beirn et al., 2011; Bonos et al., 2006). With a method in place to now purify and increase isolates of crown and stem rust fungi from KBG, researchers will have the ability to collect and maintain isolates of rust when field ratings occur, thus allowing the pathogens to be genotyped, evaluated for virulence, and screened against KBG cultivars in the greenhouse. This would give breeders the ability to correlate performance in the field with susceptibility to rust in the greenhouse. Likewise, pathologists would be able to characterize populations of turfgrass rust fungi over several years, creating a monitoring system for the emergence of new, aggressive fungal races.

\section{Literature Cited}

Agrios, G.N. 2005. Plant pathology. 5th ed. Elsevier Academic Press, Burlington, MA.

Beirn, L.A., M. Moy, W.A. Meyer, B.B. Clarke, and J.A. Crouch. 2011. Molecular analysis of turfgrass rusts reveals the widespread distribution of Puccinia coronata as a pathogen for Kentucky bluegrass. Plant Dis. 95:1547-1557.

Bonos, S.A., B.B. Clarke, and W.M. Meyer. 2006. Breeding for disease resistance in the major cool-season turfgrasses. Annu. Rev. Phytopathol. 44:213-234.

Braverman, S.W. 1965. Sources of resistance to stem and leaf rust among Phleum species. Plant Dis. Rep. 50:849-851.
Carson, M.L. 2008. Virulence frequencies in oat crown rust in the United States from 2001 to 2005. Plant Dis. 92:379-384.

Cummins, G.B. 1971. The rust fungi of cereals, grasses, and bamboos. Springer Verlag, New York, NY

Huang, D., R.C. Staples, W.R. Bushnell, and D.J. Maclean. 1990. Preparation and regeneration of protoplasts from axenic mycelia derived from the wheat stem rust fungus. Phytopathology 80:81-84.

Jackson, E.W., D.E. Obert, J. Chong, J.B. Avant, and J.M. Bonman. 2008. Detached-leaf method for propagating Puccinia coronata and assessing crown rust resistance in oat. Plant Dis. 92:1400-1406.

Jennings, D.M., B.V. Ford-Lloyd, and G.M. Butler. 1989. An aniline blue squash technique for observation of urediniospore germ pores. Mycol. Res. 92:230-251.

Pfender, W.F. 2001a. A temperature based model for latent-period duration in stem rust of perennial ryegrass and tall fescue. Phytopathology 91:111-116.

Pfender, W.F. 2001b. Host range differences between populations of Puccinia graminis subsp. graminicola obtained from perennial ryegrass and tall fescue. Plant Dis. 85:993-998.

Pfender, W.F. 2003. Prediction of stem rust infection favorability, by means of degree-hour wetness duration, for perennial ryegrass seed crops. Phytopathology 93:467-477.

Pfender, W.F. 2009a. A damage function for stem rust of perennial ryegrass seed crops. Phytopathology 99:498-505.
Pfender, W.F. 2009b. Demonstration of pathotype specificity in stem rust of perennial ryegrass. Phytopathology 99:1185-1189.

Ray, W.W. 1953. Leaf rust of Merion Kentucky bluegrass in Nebraska. Plant Dis. Rep. 37:578.

Roelfs, A.P. 1984. Race specificity and methods of study, p. 138-167. In: W.R. Bushnell and A.P. Roelfs (eds.). The cereal rusts: Origins, specificity, structure, and physiology. Academic Press, Orlando, FL.

Smiley, R.W., P.H. Dernoeden, and B.B. Clarke. 2005. Compendium of turfgrass diseases. 3rd ed. APS Press, St. Paul, MN.

Studer, B., B. Boller, E. Bauer, U.K. Posselt, F. Widmer, and R. Kolliker. 2007. Consistent detection of QTLs for crown rust resistance in Italian ryegrass (Lolium multiflorum Lam.) across environments and phenotyping methods. Theor. Appl. Genet. 115:9-17.

Vandemark, G.J. and B.M. Barker. 2003. Quantifying Phytophthora medicaginis in susceptible and resistant alfalfa with a real-time fluorescent PCR assay. J. Phytopathol. 151:577-583.

Welty, R.E. and R.E. Barker. 1993. Reaction of twenty cultivars of tall fescue to stem rust in controlled and field environments. Crop Sci. 33:963-967.

Williams, P.G., K.J. Scott, and J.L. Kuhl. 1966. Vegetative growth of Puccinia graminis f. sp. tritici in vitro. Phytopathology 56:1418-1419.

Williams, P.G., K.J. Scott, J.L. Kuhl, and D.J. Maclean. 1967. Sporulation and pathogenicity of Puccinia graminis f.sp. tritici grown on an artificial medium. Phytopathology 57:326327. 